\title{
El Fedro de Platón: un ejercicio de buena retórica engañosa
}

\author{
Plato's Phaedrus: \\ an Exercise in Good 'Deceptive' Rhetoric
}

\author{
Beatriz Bossi \\ Universidad Complutense de Madrid \\ beabossi@filos.ucm.es
}

Recibido: 27/05/2014

Aceptado: 25/04/2015

\section{Resumen}

En este artículo me propongo mostrar que lo que Sócrates hace con Fedro a lo largo de toda la obra no es otra cosa que utilizar la auténtica retórica (con su doble carga, dialéctica y psicológica) que es descrita en la segunda parte del diálogo. Las tensiones, rivalidades y celos de la situación inicial entre ellos expone un perfil representativo de relaciones entre interlocutores con perspectivas intelectuales opuestas. Es preciso disolver la resistencia emocional por medio de una serie de pasos graduales, estratégicos, y 'engañosos' (no se puede develar el propio juego desde el principio). Hay que partir de acuerdos, siquiera parciales, para continuar dialogando. Sin embargo, Sócrates también introduce nociones nuevas acerca del amor, pero éstas pasan desapercibidas a un Fedro obsesionado con la imitación de su enamorado Lisias. Hasta que Sócrates decide cortar el juego y cruzar el río. Este corte provoca un giro en ambos personajes: Fedro se dispone a escuchar lo que Sócrates quiere contarle (el mito del carro alado) y Sócrates se revela ante sí mismo como un personaje capaz de 'encantar' a Fedro con la belleza rapsódica del relato y superar su propio temor de convertirse en una bestia devoradora. Al final Sócrates muestra su juego a Fedro y le enseña cómo ha sido posible llegar a un auténtico diálogo filosófico, donde pueda tener lugar la enseñanza y el aprendizaje recíprocos.

Palabras claves: Retórica, engaño, dialéctica, rivalidad, resistencia emocional, diálogo.

\begin{abstract}
In this article I intend to show that what Socrates attempts to do to Phaedrus along the entire dialogue is nothing but persuade him by using that 'genuine rhetoric' (which
\end{abstract}


implies the knowledge of both dialectics and psychology) that is described in the second part of this work. Tensions, revalry and jelousy at the initial scene present a couple of interlocutors who have intellectual and emotional opposing perspectives. Persuasion takes place through a series of gradual 'deceptive' strategic steps (as Socrates cannot reveal his game from the start). Agreements, even partial, are required to keep the dialogue alive. Though Socrates also introduces 'new' notions, they go unnoticed to a Phaedrus obsessed with Socrates imitating his beloved Lysias. But Socrates decides to cut the game and cross the river. This provokes changes in both characters. All of a sudden Phaedrus is ready to listen to Socrates (who tells him the myth of the winged chariot) while Socrates reveals himself as capable of 'enchanting' Phaedrus with the beauty of the myth on the one hand, and of overcoming his own fear of becoming 'a devouring beast' at the same time. In the end Socrates shows Phaedrus his game in order to let him realize how it has been possible to reach a real philosophical dialogue where reciprocal teaching and learning can take place.

Keywords: rhetoric, deception, dialectic, rivalry, emotional resilience, dialogue.

\section{Introducción}

En la segunda parte del Fedro Platón define la retórica como un arte o técnica que incluye dialéctica y psicología, i.e. el conocimiento de las unidades formales

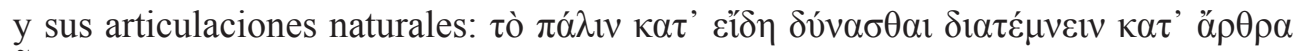
$\tilde{\eta} \tilde{\text { ñ }} \pi \dot{\varepsilon} \varphi$ por la otra, con el fin de ofrecer palabras y praxis que procuren la persuasión y

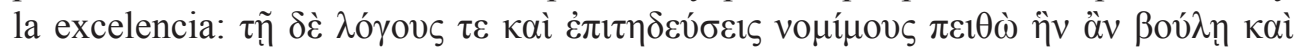

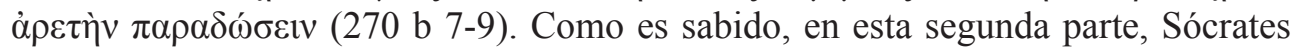
no solamente descubre cuáles son los requisitos y los fines de una dialéctica-retórica adecuada, sino que además realiza una mirada retrospectiva a fin de analizar lo que ha sucedido anteriormente en el curso del diálogo entre ellos, a la luz de los criterios expuestos en este segundo momento.

En este artículo me propongo mostrar cómo se realiza efectivamente este ejercicio retórico-dialéctico en el desarrollo mismo del diálogo entre Sócrates y Fedro. A mi modo de ver, lo que Sócrates hace con Fedro a lo largo de toda la obra no es otra cosa que utilizar la auténtica retórica con su doble carga, dialéctica y psicológica, para persuadirlo, ya que, aparentemente, esta vez Sócrates consigue su cometido: Fedro acaba por coincidir con Sócrates acerca de en qué consiste el verdadero amor y cómo ha de amar a su enamorado.

¿Cómo se produce esta persuasión? ¿Qué estrategias utiliza Sócrates para conseguirlo? ¿En qué punto del diálogo se produce el giro que permite una nueva disposición anímica? ¿Se debe la persuasión a un cierto 'encantamiento' por la fuerza narrativa del mito? ¿Cumple el relato de la palinodia las condiciones de un discurso verdaderamente filosófico, según los requisitos que el propio Sócrates pone 
de manifiesto en la segunda parte, o por el contrario, se trata de un discurso rapsódico que persuade a una mente propensa a la filosofía, pero que no enseña en forma verdaderamente filosófica porque carece de la condición dialógica? Y siguiendo en la misma dirección retrospectiva, ¿en qué medida el primer discurso de Sócrates cumple estos requisitos? ¿O hemos de creer a Sócrates cuando dice que toda la primera parte no es más que un 'juego'? ¿No será que esta descripción socrática contiene un cierto punto de ironía?

A mi modo de ver el juego de tensiones, rivalidades y celos de la situación inicial entre ellos, con toda su fuerte carga emocional, expone un perfil representativo de las relaciones entre interlocutores con perspectivas intelectuales opuestas, y es por ello que Platón se vale de ella para presentar, acaso veladamente, el verdadero problema anímico que es preciso desentrañar y depurar primero, por medio de una serie de pasos estratégicos, hasta que sea posible un auténtico diálogo filosófico donde pueda tener lugar la enseñanza y el aprendizaje recíprocos.

Considero que cuando Sócrates elabora su primer discurso cuasi mimético del de Lisias, cuando le cuenta a Fedro el mito de la palinodia acerca de aquello a lo que el alma se parece (el carro alado) y aquello que el alma persigue en su viaje a los confines del universo (el divino alimento de las formas) y cuando por fin le revela la estrategia utilizada, pone en práctica su peculiar modo de 'amar' a un Fedro encantado con los discursos bellos, a fin de 'reconducirlo', paciente y estratégicamente, hacia la mejor posibilidad de sí mismo como amante, no ya sólo de Lisias y de su discurso, ni tampoco de la belleza puramente formal y snob que este amor implica, sino de la belleza que va unida a la exploración de la verdad, la que abre un mensaje rico en posibilidades intelectuales y emocionales. Porque la verdadera retórica, es definida por Sócrates, en términos generales, como 'el arte de la conducción del alma

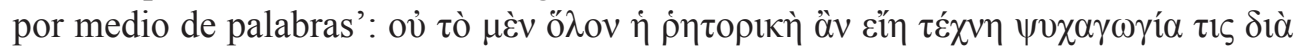
$\lambda$ ó $\omega v$ (261 a 7-8).

Ahora bien, puesto que cada alma responde a un cierto perfil divino distinto en el cortejo celeste, el recurso retórico deberá adaptarse a ella para poder conducirla. Por tanto, si realmente deseamos captar en qué consiste la buena retórica platónica, no basta simplemente con hacer un recuento de los ingredientes que conlleva o detenernos en las definiciones que se ofrecen cerca del final del diálogo. Para darnos una idea fehaciente de cómo procede el buen retórico, será necesario rastrear en detalle el modo efectivo en que esa retórica se pone en práctica en boca de Sócrates, con relación a Fedro. Por otra parte, los problemas hermenéuticos que plantea la caracterización general, especialmente en lo que la retórica tiene de 'engañosa' y de 'arte' estratégico resultan solucionables, a mi modo de ver, a la luz de lo que ocurre en el desarrollo del diálogo.

Platón teje los hilos de este diálogo de tal manera que la retórica bien ejercida usa sus armas gradualmente, de modo que el objetivo se va alcanzando parcialmente, como en una espiral ascendente, en varias etapas. El maestro que sabe, se aproxima 
poco a poco a su discípulo, como el cazador a su presa, para que no se espante (para decirlo evocando las metáforas del Sofista y del Político). Pero además, como el proceso resulta un verdadero intercambio, no sólo Fedro es alcanzado por el dardo socrático, sino que el mismo Sócrates también llega a ser persuadido, en cierto modo, por su propia decisión y por su propia retórica, cuidadosamente construida, aunque deliberadamente presentada a los ojos de Fedro como puramente 'azarosa' (265 c 9).

Espero poder mostrar cómo Sócrates se vuelve capaz de enseñar en forma progresiva, en la misma medida en que Fedro se vuelve capaz de aprender. Así Sócrates logra liberar a Fedro en dos niveles: a nivel emocional y a nivel imaginativo-intelectual. En cuanto al primer nivel, el proceso presenta dos momentos bien diferenciados: al comienzo, por medio de la 'negociación' flexible, Sócrates consigue ir ganando la confianza de Fedro, y en el momento del giro, justo antes de disponerse a cruzar el río y regresar a Atenas, por medio de la resistencia más rigurosa, Sócrates consigue producir el vacío, la ausencia, la negatividad imprescindible para que Fedro se disponga de otro modo ante él. En cuanto al nivel imaginativo e intelectual, Sócrates está dispuesto a complacer a Fedro por medio de relatos mitológicos plenos de bellas imágenes, pero no por ello desprovistas de un mensaje claro acerca de las más altas tareas a las que el alma está destinada, que indican, como una prolepsis, que el alma puede y debe amar el saber y culminar en la actividad dialéctica. Pero para que el alma de Fedro no sólo desee el saber y la compañía de Sócrates como guía en este proceso, sino que se ejercite realmente en aquello que el mito presenta como objeto de deseo posible (porque toda alma humana ha visto las Formas y por ello puede ejercitarse en recordarlas) es necesario dar un paso más. Sócrates ha de ir progresivamente introduciendo la recta interrogación refutativa.

Pero este proceso no es, me parece, un proceso unidireccional sino, como he sugerido, bidireccional. Me refiero al hecho de que, en el momento más crítico del diálogo, Sócrates cae preso, en cierto modo, de sus propias palabras: no puede abandonar a Fedro en su ignorancia y regresar a la ciudad cruzando el río, porque tiene algo que hacer con él y algo que hacer consigo mismo. Más allá de la fuerza narrativa que se deriva del hecho (o del pretexto) de que su daimon se lo impide, ya que es necesario honrar a Eros como se debe, creo que es necesario también explorar la posibilidad de que este Sócrates sepa que su relación con Fedro no puede responder al modelo del lobo frente al cordero, y que, por tanto, es necesario que él mismo supere su tensión emocional posesiva con Fedro, para poder liberarse de ataduras externas a su cometido, y reorientar su energía hacia una tarea más positiva en su aproximación a su interlocutor.

Podemos preguntarnos por qué Platón prefiere aparentemente enmascarar la intención de este giro socrático de retorno a Fedro, apelando al deus ex machina de la voz del daimon. Quizás desea presentar a Sócrates como un personaje que, aparentemente, sólo obedece al designio divino desde la sumisión, como si no fuera consciente del alcance de su estrategia, aquella de utilizar su propio giro, para hacer girar 
también a Fedro, y obligarlo a abandonar una actitud, acaso demasiado caprichosa o exageradamente dominante. Quizás esto obedece al deseo platónico de presentar a Sócrates como un hombre esencialmente piadoso, contra el juicio democrático que lo condenó. En cualquier caso, lo que pretendo mostrar es que, en el entramado del diálogo platónico, este giro tiene otras implicancias tan ricas y provocativas de cambios interesantes y necesarios en sus personajes, como la apelación a la piedad.

De modo que me propongo realizar un recorrido inverso al del diálogo platónico, comenzando por la segunda parte, a partir de la caracterización de la dialéctica y la retórica, i.e. la parte más general y teorética, que es, a mi modo de ver, el resultado y la finalidad de la primera parte. Este camino retrospectivo nos permitirá comprender mejor, creo, los signos anticipatorios que, en lenguaje cifrado, Platón deja caer a lo largo de la primera parte, para alcanzar su objetivo persuasivo/filosófico, tanto con el personaje Fedro, como con su auditorio académico.

\section{Acerca de los requisitos que debe cumplir la recta retórica 'engañosa' y de su relación con la dialéctica y con la psicología del interlocutor}

La primera dificultad que Platón señala con relación a la retórica es relativa a las consecuencias que se derivan de una retórica desligada de la sabiduría:

"Entonces, cuando el retórico que no sabe lo que es el bien y el mal se propone persuadir a una ciudad que es igualmente ignorante, no elogiando 'la sombra de un asno' con el nombre del caballo, sino elogiando el mal con el nombre del bien, y habiendo estudiado las opiniones de la multitud los persuade de hacer el mal en lugar del bien, ¿qué frutos, crees tú, que cosechará tal retórica?: ö $\tau \alpha v$ oũv ó

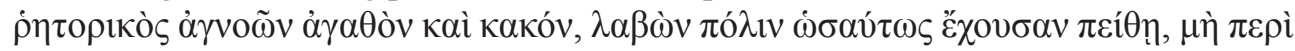

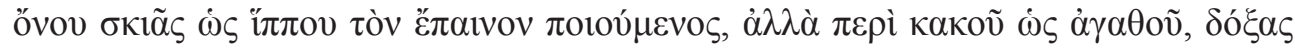

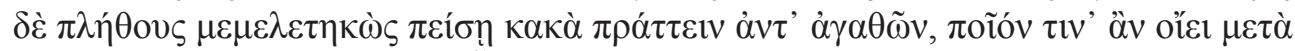

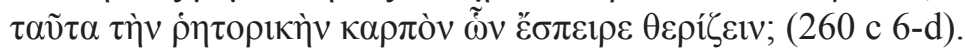

Sócrates apela al dicho espartano que asegura que el arte auténtico de la palabra se alimenta de la verdad (260 e 5-7) y advierte a Fedro que si no filosofa lo suficiente, no será capaz de decir nada sobre nada (cf. 261 a 4-59), porque la (recta) persuasión se deriva de la verdad. Pero la verdad no persuade sin el arte retórico. Esta es la otra cara de la moneda, que Platón desea enfatizar en los diálogos de madurez. La ciencia o el conocimiento de las cosas no es suficiente para persuadir a los hombres, como lo demuestra la triste experiencia del personaje Sócrates en su diálogo con Calicles o con Trasímaco. Ahora Platón se pregunta si no habrá vituperado el arte de la palabra más rudamente de lo que conviene. Por eso deja que la retórica tome la palabra y se defienda diciendo que sin ella, el que conoce las cosas, no por ello será más diestro en el arte de persuadir ( 260 d 8-9). De modo que la retórica es una técnica necesaria para que la verdad del dialéctico pueda darse a conocer y sea aceptada.

Ante el asombro de Fedro, Sócrates describe el modo de proceder de la retórica: 
Al parecer, sobre todas las cosas que se dicen, habría un único arte, si es que lo

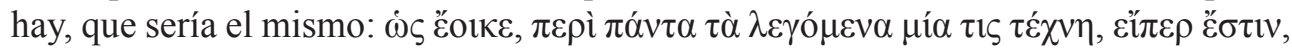
y si existiera, con este arte uno sería capaz de hacer todo semejante a todo, en la

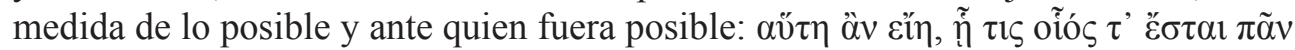

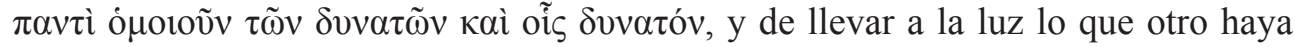

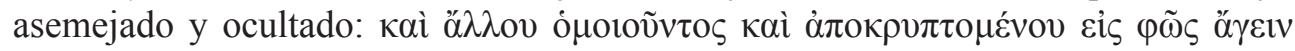
(261 e 1-4).

Por una parte, Sócrates parece sugerir que habría un único arte discursivo. Esto significa que apenas la dialéctica vuelque sus visiones en el logos, ya se integra en este único arte que abarcaría, por una parte, el conocimiento de los géneros y sus partes (dialéctica) y por la otra, el conocimiento de cómo se ha trasmitir esa verdad (retórica). Lo cual no significa que estas dos disciplinas se identifiquen, sino sólo que que se complementan y se necesitan mutuamente, aunque como veremos, no del mismo modo.

Por otra parte, Sócrates duda de que tal disciplina única, con sus dos partes, exista. Lo que probablemente marca una distancia entre el deseo de que exista y su posibilidad real, en el sentido de que una cosa es postular esta disciplina y otra muy distinta es realizarla. En cierto modo, esto podría tomarse como un obstáculo a mi interpretación, porque si Sócrates no está seguro de que pueda existir, ¿cómo podemos proceder a buscar pistas en la primera parte del diálogo, de que efectivamente Sócrates la pone en práctica? Entiendo que la objeción se resuelve si pensamos que Sócrates es el personaje que duda siempre de su saber y de las posibilidades de los saberes que postula, como una estrategia de Platón para permitir que su 'héroe' intelectual nunca deje de ser 'solamente' un amante o un aspirante del saber y no un sabiondo o un sofista. Esto, paradójicamente, fortalece su posición. Pero aunque Sócrates lo dude abiertamente en un primer momento, lo supone a continuación. Y por otra parte, tengo la impresión de que Platón lo duda mucho menos, ya que escribe un diálogo donde, a mi modo de ver, esta disciplina dialéctico-retórica se realiza, al menos en parte y siempre dentro de los límites de la capacidad humana.

Sócrates añade que este retórico debe proceder a partir de pequeñas semejanzas y no de grandes para no ser detectado y además, para ser capaz de engañar a otro y no ser engañado, ha de saber distinguir, con la mayor precisión, la semejanza o

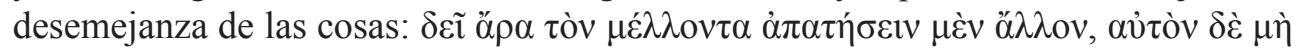

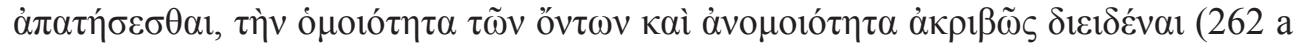
5-7). De modo que debe poseer el arte de cambiar poco a poco, pasando en cada caso de una realidad a su contraria por medio de la semejanza, y evitar caer él mismo en esto, para lo cual, es preciso ser conocedor de lo que es cada una de las cosas que

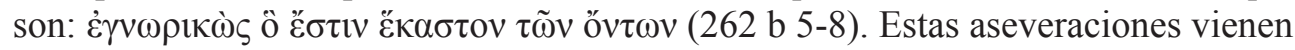
a confirmar la idea de que dialéctica y retórica se complementan y se necesitan, en cierto modo, recíprocamente, aunque, como he señalado, no son idénticas ni se necesitan del mismo modo. Si la dialéctica se mantiene en el nivel de la investigación 
personal, no requiere de la retórica. En cambio, tal como se especifica en este pasaje, la retórica siempre necesita de la dialéctica, inclusive para engañar con eficacia.

Alguien podría objetar que, en la medida en que esta retórica supone un engaño, Sócrates se estaría refiriendo al arte retórico de baja estirpe, y no a la retórica auténtica que Platón, al parecer, desea revalorizar en este diálogo de madurez. Sin embargo, este pasaje no establece una diferencia en cuanto a los fines, sino que, al parecer, describe la acción engañosa como parte del proceder de todo retórico. Esto significa que inclusive la recta retórica implica una etapa o una parte necesarimente engañosa. Aunque Sócrates da ejemplos de esta retórica fraudulenta en los tribunales cuando el que posee el arte hace aparecer lo mismo y ante las mismas personas, unas veces como justo y otras como injusto, y en las arengas políticas, lo mismo, como bueno y como malo (261 d-e), sin embargo, es posible hallar evidencia en el texto de que esta caracterización de la retórica no se refiere necesariamente a la 'mala' retórica de quien busca conocer las opiniones corrientes para complacer al auditorio.

Sócrates opone esta retórica del sutil engaño caracterizada como verdadero arte $o$ técnica, a la 'mala' retórica del que ignora la verdad, como ejercicio carente de arte o técnica:

El arte de las palabras, compañero, que ofrezca quien no sabe la verdad y va a la caza de opiniones, parece que tiene que ser algo ridículo y sin arte: $\lambda o ́ \gamma \omega v$ óp $\alpha$

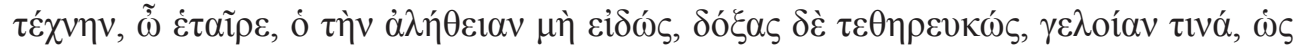

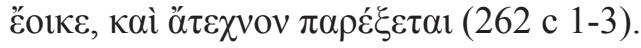

Acaso resulte oportuno señalar que cuando se dice que la retórica es capaz de conducir a la luz a quien procede gradualmente por semejanzas ocultándose, parece que se insinúa una finalidad honorable, en la medida en que se desenmascara a la retórica de quien, también sabiendo la verdad, oculta su escaramuza en las sombras hasta el final. Quien así obra desea permanecer en el engaño, porque probablemente persigue un objetivo mezquino y no la conducción de un alma hacia su excelencia. En tal sentido, observemos que una de las razones de por qué Sócrates muestra 'sus cartas' por así decir, al final del juego, al propio Fedro, podría ser que el desocultamiento de la propia estrategia resulta indispensable para que el interlocutor aprenda de su propia experiencia, con la ayuda de un interogatorio refutativo propiamente filosófico. Parecería que Platón nos quisiera indicar que cuando el alma capta algo real y lo conoce, resulta posible y necesario hacerla partícipe del juego previo 'engañoso' (en el mejor sentido de la palabra) que hizo factible su acceso a esa experiencia cognoscitiva.

Lo cierto es que tanto la retórica oculta como la manifiesta hacen lo mismo en su procedimiento: van pasando, a partir de una tesis dada, gradualmente, de semejanza a semejanza, hasta acabar en la tesis contraria. Al mismo tiempo ambas requieren que el interlocutor vaya dando su conformidad a cada paso, precisamente porque proceden sutilmente y, al parecer, agrego, sin que el interlocutor sea muy consciente de los pasos que va tomando, en una dirección contraria de la que supuestamente asume al comienzo. 
Si ambas contienen un elemento engañoso durante el proceso, parece que no podemos decir que una es mejor que la otra sino hasta conocer su finalidad, porque la diferencia entre el arte de la retórica oculta y el de la manifiesta ha de buscarse más bien en el objetivo que se persigue, sea la manipulación interesada o el bien del interlocutor que asiente. Sin embargo, esta solución podría parecer controvertida porque Platón estaría sugiriendo que el fin justifica los medios. Más bien creo que habría que evitar esta interpretación. Resulta más eficaz para comprender el presente pasaje preguntarse si el 'engaño' al que se refiere Sócrates aquí puede interpretarse como 'el uso gradual de semejanzas con el objetivo de pasar de una opinión falsa a la verdad', con lo cual el 'engaño' no sería más que parcial, temporal e instrumental y sólo existiría como tal desde el punto de vista del engañado mientras sigue inmerso en los pasos del proceso, pero no desde el punto de vista del sabio, que busca el modo de hacerle ver otras dimensiones que se le ocultan al principio, ni desde el punto de vista del resultado final para ambos interlocutores.

En el contexto inmediato de este pasaje, Sócrates señala, refiriéndose a los dos discursos pronunciados por él mismo, como ejemplos de que "quien conoce la verdad, jugando con palabras, desorienta a los que le oyen" (262 d 1-2) pero se apresura a señalar que él atribuye sus discursos a la 'inspiración' de los dioses del lugar, o a la acción de las cigarras, enviadas por las Musas, porque a él no se le da el 'arte de la palabra' (262 d 2-6). El pasaje resulta muy significativo y revelador, a la lez que una muestra de la maestría platónica para atribuir, por una parte, sabiduría de su maestro, y por la otra, seguir conservando su perfil bajo de quien sólo sabe lo que ha recibido de los dioses por lo que puede continuar pregonando su famosa consciencia de su propia ignorancia. Así oímos a Sócrates atribuirse indirectamente 'el conocimiento de la verdad', y admitir francamente que se ha permitido jugar en sus discursos, provocando un efecto 'desorientador' en el propio Fedro, aunque estos discursos tengan un origen ajeno a él. Sin duda, el efecto 'desorientador' tiene como objetivo volver a orientar a Fedro, desde el 'encantamiento' al que está sometido en su defensa absoluta del perverso discurso de Lisias, para llevarlo gradualmente, al primer discurso del propio Sócrates que le muestra que el supuesto no amante es en realidad un falso amante, i.e. uno que oculta su deseo para ser complacido, un lobo disfrazado de cordero, y en segundo término, al mito y a los bellos discursos hasta llegar aquí, al momento del desenmascaramiento de sí mismo.

En este sentido, se podría pensar en muchos juegos socráticos que han desorientado a Fedro en varios momentos del diálogo, como por ejemplo cuando no comprende el primer discurso de Sócrates y le reclama la mitad implícita, (i.e. la demostración de que el que no ama debe ser complacido por el amado). Sócrates le ha dado indicios de que no puede hacer semejante elogio del que no ama, porque el amor frío es un falso amor, y por eso, como veremos más adelante, le responde, quizás algo enigmáticamente, que ya ha hecho el elogio de ambos. Fedro no lo entiende y Sócrates, cansado de él, dice que se quiere marchar. Fedro le ruega que se quede, 
sirviéndose de excusas (el calor y la hora extrema). Sócrates lo escucha, regresa, y curiosamente, aunque menciona al daimon como causa de su retorno, le dice claramente que él, Fedro, es la 'causa' de que un nuevo discurso sea necesario. Aunque Platón le hace decir a Sócrates que se sintió avergonzado de haber cometido una falta contra el dios Eros, y que la voz de su daimon se interpuso para que no abandonase a Fedro en semejante circunstancia desafortunada, a mi modo de ver, como he adelantado en la introducción, Sócrates consigue beneficios inmediatos con esta actitud: hace que Fedro dé un giro, deje de lado por un momento su propia admiración por Lisias (al menos parcialmente) y se disponga a escuchar a Sócrates con devoción. En este punto, Platón inventa un recurso de 'juego de rol' dentro del gran juego de roles que es su propio diálogo, una especie de 'play inside the play', para aprovechar el estado de dulce entrega amorosa del 'chico' que ahora Fedro desea interpretar y que Sócrates necesita para poder llevarlo hacia la visión de una nueva dimensión del alma y de sus amores fundamentales... que encaja, hacia atrás, con lo adelantado en la introducción del primer discurso de Sócrates (e inadvertido por Fedro entonces) acerca del amor como un 'querer lo mejor' (y no sólo como un apetito ciego), y que posibilitará el procedimiento dialéctico posterior de clasificación de las locuras en divinas y humanas, y la identificación de la filosofía como un amor apasionado por el saber, como una sagrada locura, inspirada por los dioses.

Ciertamente, un momento de 'engaño deliberado' se produce cuando Fedro termina de leer el discurso de Lisias, después de haberse mostrado encandilado por su esnobismo. Sócrates no reacciona francamente censurándolo, sino que, al contrario, lo elogia calurosamente llamándolo 'genial' o 'divino' como si adivinara que la tarea de persuasión que le espera es larga y sinuosa. Más larga y más sinuosa cuanto mayor es el entusiasmo afectivo de Fedro por su enamorado Lisias.

Estos ejemplos y otros que trataremos más adelante nos hacen pensar que el supuesto 'engaño' de la buena retórica debe comprenderse en su contexto. En este sentido, Centrone ${ }^{1}$ ha observado que la palabra que Sócrates utiliza: $\alpha \dot{\pi} \alpha \dot{\tau} \eta$, traducida como 'engaño' o 'ilusión' es una noción ambivalente cuya etimología es incierta, pero una de las posibilidades es que esté relacionada con el verbo $\pi \alpha \tau \varepsilon \dot{\omega} \omega$ e indique

\footnotetext{
${ }^{1}$ Véase Centrone (2011) en su excelente artículo, 43-45. En Gorgias el autor encuentra un antecedente de un uso positivo del término que se relaciona con la tragedia, como apáte en la cual el que engaña es más justo que el que no lo hace y el que se deja engañar es más sabio que el que no se deja, es decir, que el que no se cree la trama y no disfruta de ella ni aprende de ella (82B23 DK). Este autor interpreta que la parte seria de los discursos consiste en la dialéctica, en tanto que la parte de juego consiste en la composición del himno mítico y entiende que para proponer lo serio hay que servirse de un juego engañoso. Así, Sócrates se sirve de la dialéctica sin que Fedro se dé cuenta, en el primer discurso al introducir en el alma la división entre el deseo de placer y la opinión sobre el bien y en el segundo, con la división de eros y del alma en tres partes, acaba por rebatir la tesis de Lisias de que Eros sea un mal. Centrone concluye su artículo diciendo que resulta posible interpretar muchos diálogos platónicos como ejercicios de esta retórica filosófica, entendida como desviación que se alcanza en pequeños pasos, y de un ‘engaño' positivamente orientado a la conversión del interlocutor (54).
} 
el 'llevar fuera de un camino' por lo que pueda ser traducida como 'desviación'. Desviar a alguien de un camino equivocado podría significar 'ponerlo en el camino

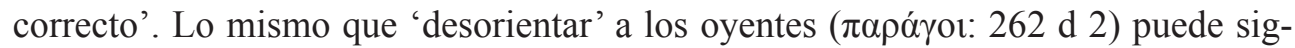
nificar 'conducirlos por otro lado', y así tener como finalidad 'volver a orientarlos'.

Por otra parte, considerando la tesis socrática de que nadie obra mal voluntariamente sino por ignorancia, podríamos especular que quien realmente supiera la verdad no podría tener como intención engañar a otro con el fin de manipularlo, porque quien supiera la verdad también sabría que todo daño a otro redunda en un daño a sí mismo. Es decir que tal retórico se engañaría a sí mismo en su proceder, caería en lo falso, en lo erróneo, y en tal sentido, aunque tuviera la técnica de la gradual transformación de las semejanzas, no poseería 'la verdad de las cosas' en sentido amplio y general. Tal vez nadie la pueda poseer en sentido estricto, y por eso Sócrates hace la salvedad: 'si tal retórica existiera' (cfr. 261 e 2).

De modo que cuando hablamos de la retórica como arte del sutil 'engaño' interpretamos que Platón se refiere, en realidad, al arte que desorienta, que quita del sendero equivocado al interlocutor, para ponerlo en la buena disposición para aprender lo que la dialéctica enseña. Este engaño progresivo de múltiples pasos es necesario porque si la verdad se presentara directamente ante sus ojos, sin velos ni grados, sería radicalmente rechazada por quien no puede percibirla, a causa de que se encuentra en la senda incierta del deambular sin rumbo fijo, encandilado por las opiniones inseguras 'de la última moda' por decirlo de algún modo.

Esta reflexión nos lleva a la siguiente característica: el arte retórico adapta el discurso al tipo de alma que tiene delante, i.e. a su grado de conocimiento o ignorancia y a sus emociones y pasiones. Es más fácil que nos engañemos en aquellos asuntos en los que andamos divagando. Por ello lo primero es identificar con agudeza a cuál de los dos géneros pertenece aquello sobre lo que se quiere hablar, sea al de las cosas discutibles, en las que la gente anda divagando, o al de las cosas estables sobre las que todos están de acuerdo. Y luego es preciso definir aquello de lo que se trata, dividiendo sistemáticamente las cosas, desde el comienzo del discurso (263 b-d).

Sócrates desea que Fedro reconozca que éste es el procedimiento adecuado, a diferencia del desordenado que ha empleado Lisias, pero, una vez más, lo hace apelando a una estrategia retórica sutilmente modesta (y engañosa). Sócrates necesita que sea Fedro quien le recuerde que ha definido al amor 'con inmejorable rigor', porque él se cuida de no atribuirse a sí mismo tal capacidad definitoria, sino que se la atribuye a las ninfas, a Pan y a Hermes (263 d-e). Quizás Sócrates asume esta 'humildad' suya característica aquí para ahorrarle a Fedro la incómoda situación de tener que aceptar que Sócrates ha vencido a su amado Lisias.

Sin dejar de invocar su propia ignorancia, Sócrates prosigue con su interrogatorio refutativo-filosófico, el mejor momento de todo el diálogo, porque necesita que Fedro reconozca que el discurso de Lisias carece de orden y que, acéfalo, empieza por el final (264 a-c). Y eso, tal vez no para humillar a Fedro, pero sí para que avance 
en su capacidad de juicio crítico, ahora que adhesión incondicional al sofista, parece haberse suavizado. Y sin embargo, Fedro se da cuenta de que Sócrates se está burlando del discurso de Lisias, que él aún considera como suyo, ya que le pregunta: '¿te

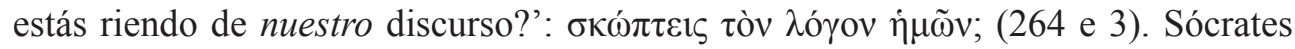
inmediatamente retrocede en su ataque 'para que Fedro no se disguste' (264 e 4). Esto nos indica que el proceso intelectual sigue al proceso emocional y que aunque se producen avances, son lentos, y es necesario tener cuidado de no herir los sentimientos del interlocutor.

Sócrates reconoce que los dos discursos por él pronunciados son, en cierto modo, contrarios: uno decía que había que complacer al que ama y el otro, al que no ama (265 a 2-3). Efectivamente, ha sido necesario admitir la tesis de Lisias provisoriamente para que Fedro no se escandalizara, cosa que hubiese ocurrido, si la tesis de su amado hubiera sido rechazada de plano por Sócrates. De modo que, para que la conducción del alma se llevara a cabo, han tenido que pasar de una tesis a su contraria, por medio de semejanzas, tal como ahora se dice que es el procedimiento habitual de la retórica.

La transformación de Fedro es gradual, porque Sócrates va oponiéndose sutilmente a la tesis de Lisias, paso a paso, introduciendo modificaciones en su propio discurso, bajo la apariencia de realizar solamente una 'imitación' del discurso de Lisias. Pero el cambio radical que permite el paso de una disposición anímica a su contraria, es la negativa de Sócrates a continuar con un juego desagradable para él, su resistencia a un mayor sojuzgamiento seductor por parte de Fedro y su decisión de cortar la conversación que no resulta ciertamente dialógica ni por tanto, filosófica (porque Fedro no se percata de los aportes introducidos por Sócrates) sino esclavizante para él. Es esto lo que pone a Fedro en la situación de dar su giro emocional hacia Sócrates, y lo que le permitirá avanzar intelectualmente con él. A partir de entonces, Sócrates desempeña el papel de amante suyo, dentro de un nuevo juego de roles, en el que la relación de amistad y rivalidad anterior es eclipsada. Durante este interludio especial, Sócrates se recupera y se halla en disposición de complacer a Fedro, en cuanto a proporcionarle bellos discursos. Esta situación más relajada y agradable para ambos, sirve como preparación al objetivo final. Es el momento en el que Fedro experimenta el modo en que Sócrates ama a los jóvenes con filosofía. Esta vivencia a su vez prepara el camino para que Fedro pueda comprender, tanto intelectual como emocionalmente, cómo se conduce un verdadero amante. Por ello, Sócrates debe actuar en el escenario del diálogo, como si él fuera realmente el amante de Fedro. Este juego le permite ofrecer un modelo de comportamiento en el que Sócrates cuida del alma de su amigo a su manera, introduciéndolo en un universo mítico que tiene efectos esperanzadores en el alma de su amigo. Y sin embargo cuando comentan retrospectivamente la palinodia y Fedro la alaba, Sócrates la considera un himno al amor que 'quizás contenga algo de verdad pero que quizás nos haya llevado en la mala dirección’ (265 b-c). 
Cuando Sócrates quiere saber cómo pasaron del vituperio al elogio de Eros, le parece que han estado jugando un juego y de las cosas que se han dicho 'al azar', rescata dos (265 c 8-10): el buscar una idea general que todo lo abarque y el dividir las ideas siguiendo sus articulaciones naturales (265 d-e).

Así resulta, utilizando el método dialéctico, que el amor pertenece al género de la paranoia, y cuando se lo divide en sus especies naturales, presenta, en su lado izquierdo, una especie siniestra que debe ser vituperada, y en su lado derecho, otra que debe ser elogiada como una forma de divina locura (266 a-b). La dialéctica, más bien tímidamente utilizada por Sócrates en la primera parte, y completamente ignorada por Fedro, es ahora puesta sobre el tapete como la clave para avanzar en el conocimiento. Ahora a Sócrates le interesa remarcar que la claridad y coherencia del discurso provienen de este método, del que se declara amante ${ }^{2}$, porque, dice, nos permite hablar y pensar (266 b 3-5), en un final que nos recuerda la conclusión de la primera parte del Parménides.

Observemos, por otra parte, que Platón pone en guardia al lector para que no tome demasiado en serio lo dicho, como tampoco lo hace Sócrates, quizás porque sabe que ha tenido que hacer concesiones a Fedro con el objeto de no contrariarlo para no perderlo. O más probablemente porque el filósofo, que es que sabe lo que sabe y lo que no, no puede tomarse muy en serio a sí mismo nunca, ya que es consciente de la posibilidad siempre temida, de errar y llevar a otros al error.

La retórica tradicional es criticada duramente por Sócrates, primero por ser de trama poco espesa en su contenido (268 a 5-6), y segundo porque esta carencia también se refleja en el modo en que provoca las emociones en el auditorio, sin conocimiento auténtico de a quiénes, cuándo y en qué medida se ha de estimular en un sentido o en otro $(268 \mathrm{~b})^{3}$. Dotes naturales, ciencia y ejercicio son necesarios para ser un retórico. En cuanto al conocimiento, se requiere investigar la naturaleza del alma para procurar las palabras y prácticas que acabarán transmitiendo la persuasión

\footnotetext{
${ }^{2}$ Para una defensa de la identificación de Filolao como la figura a la que se refiere Sócrates en 266 b 5-7 que tiene un poder natural de ver lo uno y lo múltiple, a quien él mismo dice perseguir tras sus huellas como a un dios, véase Bossi (2013).

${ }^{3}$ En una larga sección en la que Fedro insiste en apelar a los libros de retórica, desfilan los más importantes representantes de este arte: Teodoro de Bizancio, contemporáneo y rival de Lisias, Eveno de Paros, sofista y poeta, Tisias, fundador de la escuela de Sicilia, el famoso Gorgias, Pródico, Hipias, Trasímaco, Protágoras. De Tisias y Gorgias se dice que 'vieron que hay que tener en cuenta más lo verosímil que lo verdadero' (267 a 6-7; 272 d), y de hacer que lo grande parezca pequeño y vice-versa, que lo nuevo se vea como antiguo y vice-versa. De Trasímaco se dice que era capaz de indignar y calmar al auditorio con el encanto de sus palabras, por lo que era el más hábil en denigrar con sus calumnias y en disiparlas también (267 c 9-d 2). Aunque Pericles y otros les dirían que no deben irritarse con tales retóricos sino perdonarlos, Sócrates no les concede que posean el arte de la retórica porque estima que se quedan en los prolegómenos de este arte, sin entrar en materia y sin organizar el conjunto. Creen que han descubierto la retórica y escriben tratados sobre ella, pero dejan que sus alumnos tengan que procurarse los conocimientos decisivos por sí mismos.
} 
y excelencia deseadas (270 b 4-9) y para ello, hay que conocer la naturaleza en su totalidad. Sócrates llega a decir, probablemente con cierta intención de escandalizar al auditorio, que la excelencia retórica de Pericles le debe a Anaxágoras su valor, puesto que se basa en el conocimiento de la naturaleza.

En cuanto al alma, es preciso determinar tres cosas: primero, si es simple o compleja, segundo, cuál es su capacidad de actuar y de padecer algo y por quién, y en tercer lugar:

'después de haber establecido los géneros de discursos y de almas y sus pasiones, adaptar cada uno a cada una, y enseñar qué alma es la que se deja, necesariamente, persuadir por ciertos discursos y a causa de qué, y por qué a otra le pasa todo lo contrario' (271 b 1-5).

El Sócrates de Platón ejerce precisamente este conocimiento y esta adaptación al alma de Fedro. Conoce la oportunidad de decir o de callar, de hablar brevemente o en largos discursos, de provocar en él las emociones adecuadas al fin que persigue, o apelar a la ampulosidad para deslumbrarlo con la belleza de sus magníficos mitos y parangones. Se podría decir que el retórico que llega a la belleza y perfección en la posesión del arte, según esta descripción (que aparece en 272 a) es el propio Platón, quien nos advierte que todo ello no se logra sin mucho trabajo y esfuerzo (273 e).

Sócrates nos ofrece además una pista que nos permite comprender mejor el pasaje citado que se refiere al retórico que oculta su proceder (261 e 4): 'los que se ocultan' reaparecen aquí identificados con los retóricos y sofistas de moda: 'Pero los que ahora escriben sobre el arte de las palabras, a los que tú has oído, son astutos

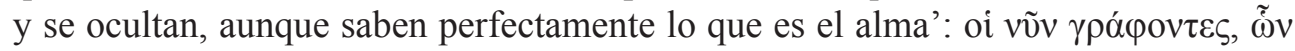

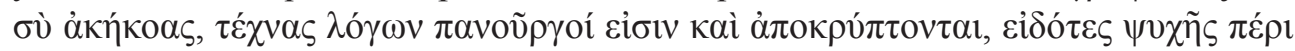
$\pi \alpha \gamma \kappa \alpha ́ \lambda \omega \varsigma$ (271 c 1-3).

Estos son los que no poseen el arte dialéctico-retórico, según Sócrates. Poseen conocimiento del alma, y en ese sentido, saben la verdad y proceden igual que los retóricos filósofos que hacen aparecer todo como semejante a todo, es decir, que van gradualmente pasando de semejanza en semejanza, desorientando o engañando al que escucha. Pero quienes astutamente ocultan su conocimiento no poseen el arte dialéctico-retórico. ¿Qué significa esta diferencia?

Si regresamos al texto, podemos observar que Sócrates dice de ellos que, aunque saben perfectamente cómo es el alma, y pueden provocar emociones según su capricho, no saben a quién, cuándo y en qué medida producirle esas emociones. Parecería que esto no es determinado por el conocimiento del alma, sino por algo superior a la psicología misma, y de lo cual ella depende. Aparentemente se trata del conocimiento de las cosas mismas, de lo que se ocupa la dialéctica.

Lo que interpreto que Sócrates intenta decirnos es que los retóricos famosos no poseen el arte de la retórica porque no poseen la dialéctica y no son filósofos, en el sentido etimológico del término, i.e. no buscan la verdad, y por eso no llevan a los que escuchan sus discursos, hacia la verdad, en cuyo caso, la dirección del gradual 
proceso de engañosa desorientación no va desde las sombras a la luz sino que se queda en las sombras, como la figura del sofista en el diálogo homónimo. Estas reflexiones quizás nos permitan comprender mejor por qué la técnica socrática refutativa y purificadora del error puede aparecer en ese diálogo como incluída en sexto lugar, entre las demás definiciones del sofista. Platón sabe que su Sócrates hecha mano de juegos engañosos y desorientadores para llevar a sus interlocutores a su dominio. Y al final del Sofista, se diferencia al sofista tradicional del filósofo solamente por el deseo de llegar a la verdad, aunque ambos hacen lo mismo, en el sentido de que producen semejanzas o imitaciones.

Análogamente, al final del tratamiento teórico de la retórica aparece explícitamente la finalidad que persigue el retórico-filósofo: ha de decir y hacer lo que es grato a los dioses, en la medida de sus fuerzas, puesto que:

Los más sabios que nosotros dicen (...) que el que tiene inteligencia no debe complacer, a no ser incidentalmente, a esclavos iguales que él, sino a sus señores, que son

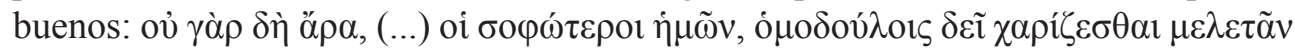

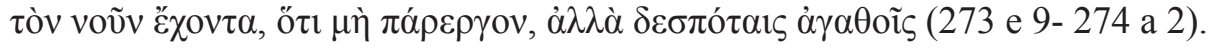

$\mathrm{Y}$ aunque esto le suponga un padecimiento: 'es bello que, quien con lo bello se

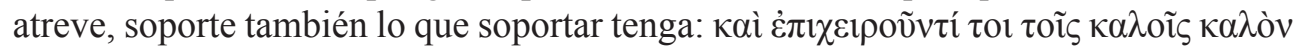

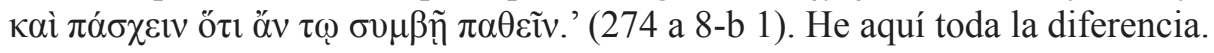

\section{Algunos pasajes significativos vistos en retrospectiva}

\section{“¿Adónde [vas] y de dónde [vienes]?”(227 a 1)}

Con esta pregunta que Sócrates hace a su compañero, sin más preámbulo, comienza el Fedro. La pregunta parece simple, inocente, como un pretexto para entablar una conversación, pero también podría interpretarse como un signo deliberado que marca una situación psicológica dinámica en la que todos nos encontramos: venimos desde nuestras creencias e ignorancias y vamos intentando abrirnos a nuevos conocimientos. La pregunta es respondida en el plano horizontal de la traslación en el espacio. La respuesta en el plano psicológico vertical de los aprendizajes no puede ofrecerse aún, sino que es el diálogo entero. Por eso allí queda suspendida, pendiente de llenarse de contenido a través de la acción dramática. Habrá una conversación, plena de encuentros y desencuentros y después, cada cual seguirá su camino. En la interacción, cada uno de los personajes recibirá una cierta revelación acerca de sí mismo y tras la plegaria y la despedida, podrá ponerse en marcha de otro modo.

En este diálogo, como también en el Lysis ${ }^{4}$, lo que dicen los personajes y lo que sucede en la acción dramática son las dos caras de un mismo tejido. Porque no es sólo que Fedro lee un discurso escrito por Lisias, acerca la conveniencia de complacer al que no ama, sino que el mismo Fedro está preso de la retórica vanguardista y snob de

\footnotetext{
${ }^{4}$ Bossi (2000).
} 
Lisias que persigue el máximo de placer con el mínimo de complicaciones, disfrazada de respeto y discreción. Y no es sólo que Sócrates compone un discurso aparentemente semejante al anterior para complacer a Fedro. Es que en ese primer momento, Sócrates no puede hacer otra cosa que simular (engañosamente) que está formalmente de acuerdo con el discurso, porque compite con Lisias por la atención de Fedro, i.e. porque está, como él mismo declarará más tarde: "envenenado" por él (242 e 1)5. Mover a Fedro desde su embeleso inicial y persuadirlo de un cambio de rumbo requerirá de toda la sutileza estratégica de Sócrates y aún así, de un primer intento que acaba en fracaso.

"Si yo no conozco a Fedro, también de mí mismo me he olvidado" (228 a 5-6)

Fedro provoca a Sócrates poniendo a Lisias en un pedestal de habilidad: lo llama deinótatos: "el habilísimo" o también "el más terrible"6 (228 a 1). Fedro se hace de rogar: él no se acuerda de todo lo que el gran Lisias ha escrito. Sócrates lo desenmascara diciendo: "si yo no conozco a Fedro, también de mí mismo me he olvidado". Sócrates sabe que Fedro se sabe de memoria el discurso y quiere lucirse con él. Fedro le devuelve la frase: "si yo desconozco a Sócrates es que me he olvidado de mí mismo" un poco más adelante, porque a pesar de las reticencias de su amigo, sabe que desea hacer un discurso.

Terminada la lectura del argumento de Lisias, Sócrates encontrará el discurso "genial" ( $234 \mathrm{~d} 1)$ y confesará haber seguido y haber entrado en delirio báquico al

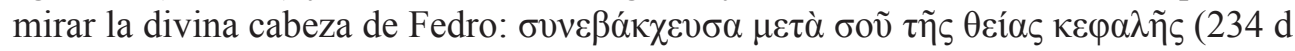
5). Parece que este Sócrates no podrá decirle abiertamente lo que piensa de su contenido y aparentemente se limitará a hacer observaciones formales. ¿Por qué Sócrates no hace su trabajo? ¿Por qué no lo refuta abiertamente, ni lo pone en su sitio, ni lo humilla para enseñarle? Fedro está encandilado por el discurso de Lisias y es incapaz de someterse a la prueba de la refutación, y de recibir la verdad sin tapujos. Pero además, el mismo Sócrates se ve obligado a entronizar a Fedro, y a no contradecirlo, porque está bajo el efecto del 'veneno' de Fedro.

Pero Sócrates está decidido a no perder el tiempo (analizando los mitos tradicionales) y en cambio quiere investigarse a sí mismo y saber si se ha vuelto una fiera

\footnotetext{
${ }^{5}$ A pesar de que la atmósfera de seducción nos podría hacer creer que Fedro es el joven potencialmente amado de Sócrates, por su edad (entre los 30 y los 40 años) le corresponde el papel de amante, y así se manifiesta en el transcurso de la obra: Fedro aparece como el amante de Lisias y Sócrates, al final del diálogo, es presentado como el amante de Isócrates (279 b 1-3). De este modo se da por supuesto que Sócrates aboga, no por el amor de Fedro, sino por convertirlo en un amante de la sabiduría y por apartarlo de la retórica perversa de los sofistas. Aunque esta finalidad intelectual sea efectivamente operativa, no podemos ignorar el ambiente deliberadamente encantador y los deliciosos juegos de halagos y celos, especialmente manifiestos en los interludios, que nos indican una relación de complicidadrivalidad estrecha entre los dos amigos.

${ }^{6}$ No es casualidad que Sócrates calificará con este mismo adjetivo a quienes no se creerán la prueba de que el amor es una locura que nos es dada por los dioses para nuestra mayor fortuna (245 b-c). También se aplicará, como veremos, al discurso de Lisias y al primer discurso de Sócrates, con el sentido de 'temible'.
} 
más enrevesada y más hinchada que Tifón o bien es un viviente más pacífico y más sencillo, quien por naturaleza participa de un cierto don o destino divino 'no-altivo':

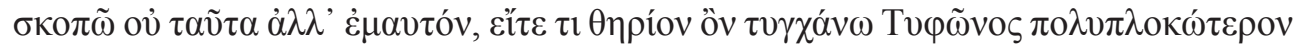

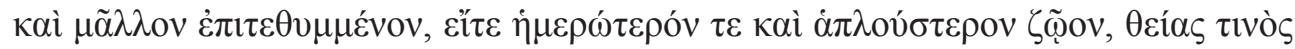

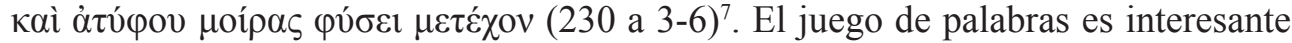

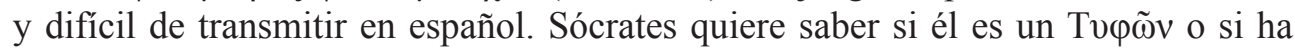
recibido un lote divino que lo hace de una naturaleza ö́vழos: no arrogante, no lleno de aires altivos.

Teme haberse convertido en un hombre tortuoso, dominado por múltiples y contrarios deseos, un ser orgulloso, presumido (lleno de humos), y peligroso que destruye todo cuanto toca. Pero no está seguro de ser así, quizás, por el contrario, ha llegado a ser un hombre más civilizado y más sencillo, i.e. gobernado por un solo principio, capaz de participar de lo divino y sin humos. En términos comparables al esquema tripartito del alma en la República, lo que Sócrates se pregunta es si lo que domina en él es la multiplicidad de apetitos en lucha, unida al orgullo siempre listo para henchirse de aires y enfurecerse por nimiedades (su parte irascible), o si es capaz de controlar los apetitos, y liberarse de toda altivez y orgullo destructivo. La preocupación de Sócrates puede también constituir una anticipación, en clave personal, de la imagen del alma como carro alado y así podemos preguntarnos, siguiendo el esquema de héroes contra villanos: ¿será este Sócrates un auriga capaz de conducir su carro y el de se amigo Fedro a su destino divino, o su caballo negro, deseoso de bajar a la dulce tierra de los dones que satisfacen los apetitos, y quizás enceguecido de celos por verse obligado a competir con otros carros (como por ejemplo, el de Lisias) destrozará las alas propias y ajenas? Con seguridad cualquier lector de Platón sabe la respuesta. Pero lo que nos interesa aquí es explorar el modo cómo Sócrates (conducido por Platón) lleva a cabo su empresa y cuáles son las condiciones o requisitos del alma del amante que guía y del alma del amado que, en esta escena inicial, se resiste a ser conducido...

Este Sócrates no parece de entrada el maestro que conducirá la discusión con seguridad completa en su capacidad para refutar, mostrando directamente la verdad, como lo hace el protagonista del Protágoras o del Gorgias, quien, a mi modo de ver, no logra persuadir verdaderamente a ninguno de los personajes homónimos ni tampoco a Calicles, aunque aparentemente logre vencer a los dos primeros. La paradoja es que este Sócrates, más bien tentativo y herido por la exaltada devoción de Fedro hacia la retórica de Lisias y hacia su persona (cfr. 234 e), este Sócrates que nos sorprende y quizás hasta nos irrita porque a la hora de dar su juicio sobre el discurso de Lisias, se muestra, en principio, adulador y evasivo, será el que logre persuadir a Fedro. ¿Por qué? A mi modo de ver porque el Platón maduro sabe que es preciso

\footnotetext{
${ }^{7}$ Un Tifón es un monstruo de cien cabezas y terrible voz, una fiera henchida de humos, que se manifiesta en la erupción furiosa y devoradora de los volcanes (Il. II 782; Teog. 820 ss.).
} 
proceder con cautela, siguiéndo la corriente del interlocutor, 'engañándolo' progresivamente para lograr su confianza, e ir inroduciendo las desemejanzas no deseadas en el entramado de las imitaciones deseadas por el interlocutor, paulatinamente. Aunque la estrategia en esta etapa resulte inútil porque Fedro se presenta inmune a las 'desemejanzas' con relación al discurso paradigmático de Lisias y oye sólo lo que desea, sí le es útil, en cierto modo, a Sócrates para no provocar una ruptura indeseable y prematura.

Un momento de discrepancia es aquel en el que, cuando Fedro provoca a Sócrates al poner a Lisias por las nubes (235 b), Sócrates se resiste a condescender con él, y reconoce el valor superior de otros poetas. En un 'velado' arrebato de sinceridad, lo llama 'amadísimo' y 'hecho de oro' si cree que está diciendo que Lisias se equivocó completamente. Pero tras revelar francamente a Fedro lo que realmente piensa, este Sócrates cauteloso vuelve a refrenarse diciendo que él cree que eso no se le ocurriría ni al peor de los escritores ${ }^{8}$. Antes de la palinodia, este Sócrates da la impresión de comportarse, en parte, como el amante adulador, temeroso de granjearse la enemistad de Fedro, exactamente como el modelo de amante apasionado que Lisias combate, cuyo deseo le ofusca la mente (233 a). Las evasivas de Sócrates en este interludio, su reconocimiento de ignorancia, su deseo de no contrariar a Fedro y su temor a avergonzarse delante suyo son comúnmente interpretados como signos anticipatorios de que el primer discurso de Sócrates será una imitación del de Lisias, formalmente mejorada, pero igualmente falsa y blasfema en cuanto al contenido.

Y sin embargo, a cada paso, intercaladas con las actitudes timoratas, hallamos que Sócrates, en sus arrebatos de sinceridad, también ofrece cifrados mensajes contrarios al pensar y el sentir de Fedro. Esta ambigüedad en su actitud nos hace pensar que Sócrates teme tanto a su propio Tifón que realmente piensa que el mirar a Fedro durante su primer discurso supuestamente imitativo del de Lisias, podría perturbarlo al punto de obligarlo a decir lo que no quiere, con tal de complacer a su amigo. De modo que me parece que no es por proteger a Fedro que Sócrates se cubre la cabeza, ni tampoco porque siente vergüenza delante suyo de tener que decir lo que no es verdad, sino todo lo contrario, se cubre para protegerse a sí mismo de la influencia de Fedro 9 , i.e. para poder decir sin reticencias lo que Fedro no quiere escuchar. La

\footnotetext{
${ }^{8}$ Pieper 1964, 29: "La ironía añade ciertas dificultades a la conversación. Si estamos tratando con alguien a quien le agrada hablar con marcas irónicas, simular que es estúpido cuando está construyendo un argumento poderoso, y hacerse el entusiasta mientras practica una crítica incisiva, entonces debemos ser infernalmente cuidadosos... Este es exactamente el modo cómo debemos conducirnos con el Sócrates de Platón".

9 Tejera $(1992,291)$ señala que Sócrates está bloqueado, "vencido por el erotismo de la situación", resistiendo la sexualidad de su respuesta y observa que los intérpretes que no ven este punto son injustos con la actitud de auto control de Sócrates, quien encasta su respuesta en una narración acerca de un perseguidor y un perseguido para tomar distancia del discurso de Lisias (Schaerer 1938; De Vries 1969; Cooper 1938; Fowler 1914). También para Helmbold y Holther (1952, 388) Sócrates corteja a su
} 
paradoja es que Fedro, quien no da la menor importancia al gesto, lo escuchará creyendo que la hipótesis de Lisias está a salvo.

Sócrates intenta abrir los ojos de Fedro en la introducción de su discurso, al revelar la verdadera intención del supuesto "no amante". Declara que aunque "hacía ver como si no lo quisiera" (237 b 2-5) el astuto supuesto no amante estaba igual de enamorado que los demás (i.e. perseguía lo mismo que cualquiera: el placer sexual). Además, Sócrates presenta dos principios que nos rigen y conducen: el apetito natural de placeres, que describe como 'en sí mismo ni bueno ni malo', y la “opinión adquirida que tiende a lo mejor". A veces estos poderes están en armonía en nosotros, otras veces luchan y se oponen entre sí y a veces domina uno y a veces domina el otro. Si nos conduce la opinión de lo mejor, con raciocinio, y resulta más poderosa, este poder recibe el nombre

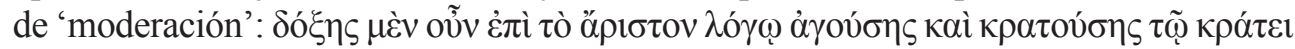
$\sigma \omega \varphi \rho о \sigma u ́ v \eta ~ o ้ v o \mu \alpha(237 \text { e })^{10}$. En cambio, cuando el apetito irracionalmente nos arrastra

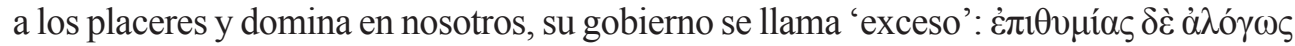

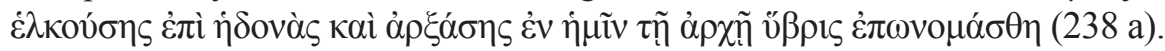

Da la definición más corriente de "eros" como el apetito que, sin estar acompañado de la opinión racional sobre lo que es recto, domina impulsado ciegamente hacia el placer de la belleza y, fortalecido por otros apetitos con él emparentados, es arrastrado hacia la belleza de los cuerpos y consigue la victoria.

Este Sócrates en apariencia más vulnerable, inseguro, y enamoradizo que se distancia del gran Maestro de los diálogos de juventud que vencía sin convencer, y que cansaba a sus interlocutores por su jactancia y sus deseos encubiertos de victoria a toda costa, este Sócrates más humano y cercano despliega sutiles estrategias escénicas para rechazar indirectamente los juicios de valor de Lisias. Ha dicho lo suyo, y empieza a sospechar que tal vez logre vencer a su propio Tifón. Pero ha hablado tan discretamente que tendrá que enfrentarse a la amarga experiencia de comprobar que el propio Fedro no se ha percatado en absoluto de que su discurso anticipa principios que acabarán con la retórica encubierta de Lisias.

Sócrates acaba entusiasmado el preámbulo de su discurso, donde se puso como objetivo determinar primero la naturaleza del amor para estar en condiciones de establecer si es beneficioso o dañino. Siente que al hablar ha experimentado un trans-

interlocutor en una atmósfera emocional cálida, con múltiples alusiones al eros paidikos.

${ }^{10}$ Aquí la 'moderación' es el poder que tiene la opinión sobre lo mejor para conducirnos racionalmente. De modo que la razón define lo que es mejor y nos conduce, porque tiene el poder de hacerlo y ese poder que 'salva al pensar' según la etmología platónica, es la $\sigma \omega-\varphi \rho \sigma v \dot{v}$. En este diálogo, aparece íntimamente ligada al conocimiento, ya que es la fuerza que da el poder a la opinión para convertirla en principio activo. Pero al parecer no se identifica con el conocimiento de lo bueno ni con el conocimiento de uno mismo como en el Cármides sino que esta excelencia es definida como un poder. La diferencia entre una vida moderada y una vida excesiva estriba en el poder o la carencia de poder con que cuenta la razón para tomar las riendas de la vida.Trabattoni $(2011,292)$ enfatiza este modo ordenado, proporcionado, medido, y por tanto, bueno, de satisfacer el deseo natural de placer. 
porte divino, que el lugar también es divino, que a menudo va a ser arrebatado por las ninfas a lo largo de su discurso, y de Fedro no se sorprenda de esto porque ya

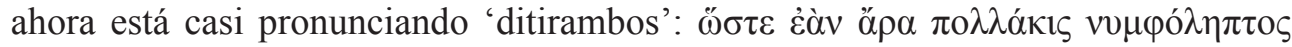

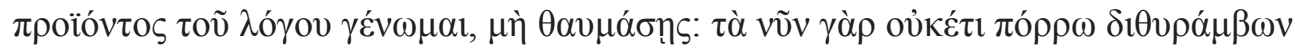
$\varphi \theta \dot{\varepsilon} \gamma \gamma o \mu \alpha 1$ (238 d) y atribuye la causa de su estado al mismo Fedro. E inmediatamente después le pide que escuche lo que sigue porque: "quizás pudiéramos evitar eso que me amenaza".

¿Por qué Sócrates se siente tan fuerte? ¿Qué significa este vocabulario emparentado con las ninfas y con el culto de Dionisos? ¿Qué es lo que lo amenaza? A mi modo de ver, Sócrates ha experimentado como un arrebato de elocuencia, porque se ha atrevido a decir lo que deseaba fervientemente comunicar a Fedro desde hacía un buen rato, como en un grito para quitarle la venda de los ojos. Ese matiz báquico de su entusiasmo nos recuerda que una de las posibles etimologías de 'Di-tirambo' refieren al momento en el que el mismo Zeus arrebata del fuego inmortal a su hijo Dionisos para salvarlo, introduciéndolo en su cadera, al tiempo que le grita que entre y que lo hará ilustre en Tebas de modo que reciba este nombre (Eurípides, Bacantes, 520-530). Quizás Platón tiene en mente este pasaje, pero lo cierto es que Sócrates parece tener una intención análoga con relación a Fedro: quiere salvarlo del fuego de una pasión perversa y tal vez presiente que, si lo consigue, él mismo se salvará también de la amenaza que lo atemoriza, aquella de convertirse en una bestia destructiva como Tifón. Soy consciente de que estoy en el terreno resbaladizo de las especulaciones acerca de intenciones de los personajes, no manifiestas en el texto. Pero estas relaciones quizás puedan dar un cierto sentido, a las palabras misteriosas de Sócrates.

El discurso de Sócrates y el de Lisias coinciden textualmente en rechazar el amor excesivo, posesivo y manipulador, y en valorar positivamente el deseo sexual natural gobernado por la opinión racional sobre lo mejor, i.e., auto controlado. Tres veces Lisias enfatiza este aspecto de la conducta de que no ama: 1) no obra por necesidad sino voluntariamente, deliberando sobre lo mejor (231 a 4-5); 2) siendo dueño de sí mismo, elige lo que realmente es mejor (232 a 4-6) y no será dominado por el eros sino por sí mismo (233 c 1-2). Pero, a mi modo de ver, no sostienen realmente la misma tesis, porque Sócrates se ha dado cuenta de que el no amante es un farsante que persigue lo mismo que el otro, el placer sexual sin más, i.e. sin la supuesta amistad y consideración que Lisias pregona a favor del que no ama (233 a y 233 c-d) y de que utiliza una apariencia de autodominio para obtener más fácil y eficazmente, lo mismo que el otro. En este sentido, el análisis de las ambigüedades psicológicas de Sócrates conduce a la conclusión, ya defendida por Friedländer $(1960,207)$, de que la intención del primer discurso de Sócrates, lejos de limitarse a revisar formalmente el discurso de Lisias, consiste en desenmascarar los peligros del mensaje del hablante. En esta misma línea, Calvo $(1992,50)$ entiende que este discurso es 'profundamente verdadero'. Es evidente que, puesto que al comenzar la narración, Sócrates identifica 
al amante como el que está dominado por el deseo encubierto de placer, a partir de allí, nada puede haber de rescatable en la larga descripción de su mezquina conducta con el amado, que se resume en la sentencia final: "como a los lobos los corderos, así aman los amantes a los mancebos" (241 d 1), a pesar de las apariencias de ser un amante 'políticamente correcto, liberal y respetuoso'.

En la segunda parte del diálogo, Sócrates criticará severamente su primer discurso, juzgando que no es 'ni sano ni verdadero' (242 e 5-243 a 2). Estoy de acuerdo con Ferrari en que, sin embargo, "no reniega, en retrospectiva, de su contenido sino sólo de su falta de integración en una perspectiva más amplia" (Ferrari, 1987, 112). Podemos comprender que a Sócrates le parezca que su discurso ha sido demasido "simple" y, en alguna medida, impío porque ha presentado una simplificación unilateral del amor al querer seguir 'engañando' a Fedro en la apariencia de que la tesis de Lisias era aceptable. Por ello, a pesar del preámbulo que sí dice algo verdadero, en el cuerpo del discurso, en cambio, se ha visto 'obligado' a tomar a eros en su acepción vulgar o corriente como 'mero apetito de placer sexual', por lo que luego juzgará que ninguno de los discursos, ni el suyo ni el de Lisias "ha dicho nada sano ni verdadero" aunque así lo pareciesen. Esta visión parcial, utilitarista y mezquina, no muestra la grandeza del amor. Sócrates atribuye su primer discurso a la presión de Fedro y le recrimina que éste lo hubiera "envenenado", con fuertes celos.

Volviendo a la escena del final de su primer discurso, cuando Sócrates da por terminado, se niega rotundamente a continuar: "no vas a oír de mí ninguna palabra más" y le dice: "atravieso este río y me voy antes de que me fuerces a algo más difícil” (242 a 1-2)

Fedro se ha quedado estupefacto porque esperaba que Sócrates cantara las ventajas de complacer al que no ama. Es evidente que Sócrates no puede hacer esto, por lo que desea desembarazarse de él rápidamente, dándole dos justificaciones: 1) "lo contrario de aquello que hemos reprobado en el uno es lo bueno propio del otro" (241 e 5-6) y 2) "ya se ha dicho de ambos lo suficiente" (241 e 7) por lo que no hay necesidad de prolongar el discurso. Tanto el que ama como el que supuestamente no ama, persiguen su propio placer egocéntrico, de modo que no puede concluirse que el amado deba complacer a uno, y no al otro, porque ambos persiguen lo mismo con diferentes estrategias y ninguno parece realmente cuidar del amado con un amor auténtico. Cuando Sócrates se da cuenta de que Fedro no ha comprendido el mensaje, que no acepta que el no amante es un farsante, y que le resulta indiferente la distinción dialéctica entre la opinión acerca de lo mejor y el deseo de placer, parece que se da por vencido, al decir que su relato "sufrirá la suerte que le corresponda".

Ahora Sócrates parece desear marcharse imperiosamente. En un momento de exaltación y franqueza, ha logrado que su parte 'no-arrogante' venciera para intentar abrir los ojos de Fedro a fin de que éste se diera cuenta de las verdaderas intenciones ocultas del amante del discurso de Lisias (y quizás también, del propio Lisias). Es posible que Sócrates tuviera la esperanza de que su amigo hubiera comprendido, 
pero a pesar de haber cuidado muy especialmente de no contrariarlo frontalmente, y a pesar de haber intentado persuadirlo sutilmente, Fedro está empecinado en la conveniencia de que el amado complazca al que no ama. Esta es la hora más baja del diálogo en la que Sócrates pierde la paciencia, ya no puede soportar más contemplaciones con las ideas que Fedro espera que él comparta y defienda, y al parecer, la incertidumbre o la indignación lo vencen, porque a pesar de su estrategia y de su esfuerzo nada ha sido suficiente para despertar a Fedro de su espejismo.

En cualquier caso, la cautivante mascarada de las palabras ha terminado. Hay que pasar a la acción. De modo que empieza a cruzar el riachuelo y entonces Fedro, intenta persuadirlo de que se quede y sigan dialogando. Sócrates se gira, le alaba su capacidad persuasoria graciosamente y le revela, para su asombro, que "ha llegado a ser la causa de que todavía haya que pronunciar otro discurso". Fedro se alegra de que Sócrates ya 'no le haga la guerra' y está dispuesto a escucharlo de otro modo.

El amor de amistad que siente Sócrates por Fedro se va revelando, a partir del giro socrático, como algo cada vez más serio, sólido y comprometido. No podemos interpretar la relación entre ellos en clave erótica exclusivamente ${ }^{11}$, por una parte, porque el diálogo termina presentándolos como dos amigos que todo lo tienen en común, porque son amantes adultos con sus respectivos jóvenes amados, y porque el divino eros filosófico no marca tanto la relación recíproca entre ambos personajes, como la común inspiración de ambos hacia un objeto de contemplación intelectual. Y sin embargo, en este momento, quizás el más crítico del diálogo, los vemos desbordarse emocionalmente en una especie de breve actuación dentro de la acción o "play inside the play", como hemos adelantado en el apartado anterior, cuando Sócrates se dirige a Fedro como si fuera su joven amado: “¿Adónde se me fue, ahora, el muchacho con el que hablaba? Para que escuche también esto y no se apresure, por no haberlo oído, a conceder sus favores al no enamorado" (243 e 4-6)

Fedro le sigue la corriente, correspondiéndole dócilmente como si Sócrates fuera $s u$ amante, al tiempo que le contesta solícito con un: "aquí está, siempre a tu lado, muy cerca, cuando tú quieras" (243 e 7-8). La respuesta de Fedro marca el paso hacia la manifestación de un deseo profundo de apertura mental, interés y consideración

\footnotetext{
${ }^{11}$ Nussbaum $(1986,204 ; 211)$ cree que Sócrates es el amante por excelencia y que Fedro es el amado complaciente, y ve en este episodio una confesión de apertura al amor loco y divino entre ellos. Gooch (1992, 309-312) ha rebatido esta interpretación mostrando que el motivo de la relación, marcada por el lenguaje durante todo el diálogo, es siempre de compañerismo y amistad, y que, al final, los personajes no emprenden una vida en común, sino que retornan a sus respectivos amados, no sólo para apreciar la belleza en ellos sino para convertirlos al verdadero amor de la sabiduría. Sólo cuando el amante controla su caballo negro, y es capaz de ver en el amado aquella Belleza sentada en su trono junto a la Moderación, a ambos les crecen las alas del alma para permitirles el ascenso. (Para una defensa anterior de esta misma interpretación, véase De Vries 1969, 113.)
} 
por el contenido del mensaje socrático, que deja atrás al Fedro rival, distraído, indiferente y superficial ante los intentos de Sócrates de curarlo de su ceguera ${ }^{12}$.

\section{A modo de Conclusión}

Ahora estamos en condiciones de comprender por qué Fedro es la causa profunda del regreso de Sócrates: Fedro necesita aprender lo que es el verdadero y libre amor para poder curarse de la seducción del farsante, de la que no pudo librarse con el discurso de la censura del amor vulgar ${ }^{13}$. Y lo aprenderá emocionalmente con otra narración mítica y con el amoroso cuidado de Sócrates, o quizás habría que decir, lo aprenderá porque el relato presenta a su imaginación algo que es un objeto de deseo para Fedro, y porque quien se lo dice ha pasado las pruebas de su empecinamiento con resistencia y esperanza. Al final, si Sócrates es capaz de persuadir a Fedro, esto se debe no sólo a su pericia para ponerle las preguntas adecuadas, sino también a su actitud. Sócrates ha dejado atrás sus celos, y las instigaciones competitivas de Fedro, hasta quitarse la máscara de condescendencia engañosa para revelarse, tras la 'rendición' de Fedro, como un verdadero maestro-amante.

Así, creo haber intentado mostrar cuáles son los pilares del largo proceso de educación de Fedro por parte de Sócrates y del proceso de fortalecimiento de Sócrates a partir de su experiencia reveladora de sí mismo como posible maestro de Fedro. Sin duda el proceso no consiste en transmitirle conocimientos para que Fedro los retenga en su memoria. Muy por el contrario, se trata de empezar por cambiar la disposición anímica de Fedro, introduciendo gradualmente desemejanzas y contrastes. Fedro no los capta. Sócrates corta el juego de rivalidades y celos. Se produce el giro. Fedro se dispone a escuchar a Sócrates. El mito y la belleza de los discursos de la palinodia sirven de antesala para preparar a Fedro a la verdadera revelación. A mi modo de ver, esta se produce cuando, por medio de un interrogatorio refutativo, se presentan ante Fedro los mecanismos y las características esenciales de la dialéctica-retórica que

\footnotetext{
${ }^{12}$ Hackforth $(1952,53)$, contra Friedländer, no considera que la velada sugerencia de Sócrates de que Fedro es efectivamente el amado, y la aceptación por parte de Fedro de este papel, sea otra cosa que un juego. A mi modo de ver, aunque la finalidad de la relación entre los personajes no sea predominantemente erótica, esto no significa que no pueda contener algunos elementos que podríamos situar en el límite entre lo propio de las relaciones amistosas y el inicio de las relaciones eróticas. Sócrates enseña a Fedro a desempeñar acaso por imitación el papel de amante enamorado de su amado y de la filosofía; esto requiere reencauzar su relación con Lisias y demandar a su amado: "que escriba que es al que ama, más bien que al que no ama, a quien, equitativamente, hay que otorgar favores" ( $243 \mathrm{~d}$ 5-7) porque el amante es el que predominantemente cuida y enseña. En este sentido, como cuidador y maestro, podríamos decir que Sócrates desempeña el papel de amante de Fedro, para que éste haga lo propio con su amado.

${ }^{13}$ No estoy en absoluto de acuerdo con Griswold $(1986,71)$ en que "la explicación de Sócrates de por qué debe pronunciar otro discurso sugiere que a él le concierne más su propio bienestar espiritual que el de Fedro".
} 
Sócrates ha intentado poner en práctica, siquiera parcialmente, en el diálogo anterior, a fin de provocar los cambios emocionales e intelectuales necesarios para conducir a Fedro al corazón del desocultamiento y de la filosofía. Desde mi punto de vista Sócrates ha conseguido plantar en Fedro y en sí mismo, las semillas inmortales y fecundas que crecen solas y hacen felices a los hombres:

"Pero mucho más noble es ocuparse con seriedad de estas cosas, haciendo uso de la dialéctica. El dialéctico elige un alma adecuada y planta y siembra en ella palabras acompañadas de sabiduría, capaces de ayudarse a sí mismas y a quienes las plantan, las cuales no son estériles, sino portadoras de simientes de las que surgen otras palabras en los caracteres de otros. Tal discurso vuelve a la semilla inmortal para siempre y al hombre que la posee lo hace feliz en el grado más alto posible para un

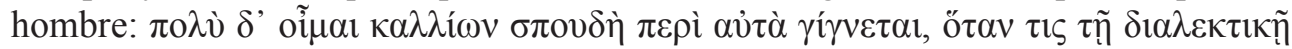

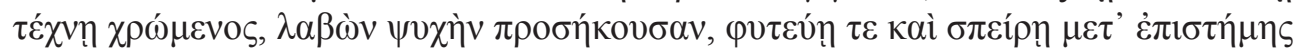

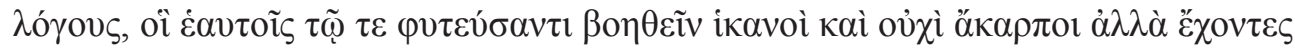

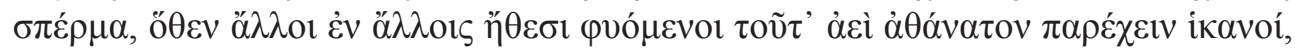

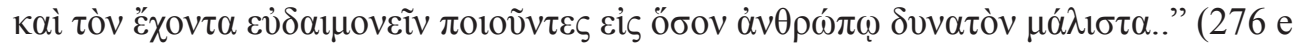
4-277 a 4). 


\section{Bibliografía}

Bossi, B., 2000: "Is the Lysis really aporetic?" in T. Robinson - L. Brisson, (eds.), Plato, Euthydemus, Lysis Charmides, Proceedings of the V Symposium Platonicum, Selected Papers, Sankt Augustin, 172-179.

"Philolaus and Plato on Method, Measure and Pleasure", in G. Cornelli, R. McKirahan and C. Macris (eds.) On Pythagoreanism, Berlin, 2013, De Gruyter, pp. 271-306.

Calvo Martínez, T., 1992: "Socrates's First Speech in the Phaedrus and Plato's Criticism of Rethoric", in L. Rossetti (ed.), Understanding the Phaedrus, Proceedings of the II Symposium Platonicum, Sankt Augustin, 47-60.

Centrone, B., "Fedro 261 e7-262c4, o l'inganno della buona retorica" in G. Casertano (ed.), Il Fedro di Platone, Napoli, 39-55.

De Vries, G.J., 1969: A Commentary on the Phaedrus of Plato, Amsterdam.

Ferrari, G.R.F., 1987: Listening to the Cicadas, A Study of Plato's Phaedrus, Cambridge.

Friedländer, P., 1960: Platon, III, Berlin.

Gooch, P., 1992: “Has Plato changed Socrates' heart in the Phaedrus?", in L. Rossetti (ed.), Understanding the Phaedrus, Proceedings of the II Symposium Platonicum, Sankt Augustin, 309-312.

Griswold, C., 1986: Self-knowledge in Plato's Phaedrus, New Haven and London.

Hackforth, F.B.A., 1952: Plato's Phaedrus, Translated with an Introduction and Commentary, Cambridge.

Nussbaum, M., 1986: The Fragility of Goodness, Cambridge.

Pieper, J., 1964: Love and Inspiration, A Study of Plato's Phaedrus, London.

Rowe, C., (1989) "The Unity of the Phaedrus: a Reply to Heath" in J. Annas (ed.) Oxford Studies in Ancient Philosophy, 7, 175-188.

Sinaiko, H., 1965: Love, Knowledge and Discourse in Plato: Dialogue and Dialectic in Phaedrus, Republic and Parmenides, Chicago and London.

Tejera, V., 1992: "The Phaedrus, Part I: A Poetic Drama", in L. Rossetti (ed.), Understanding the Phaedrus, Proceedings of the II Symposium Platonicum, Sankt Augustin, 290-295. 
Trabattoni, F., 2011: "Un'interpetazione 'platonica' del primo discorso di Socrate nel Fedro" in G. Casertano (ed.), Il Fedro di Platone, Napoli, 285-305.

Yunis, H., 2011: Plato, Phaedrus, Introduction and Commentary, Cambridge.

\author{
Beatriz BossI \\ Universidad Complutense de Madrid \\ beabossi@filos.ucm.es
}

